\title{
Sistemas Tutores Inteligentes: um Mapeamento das Produções Brasileiras
}

\author{
Arcanjo Miguel Mota Lopes, José Francisco de Magalhães Netto \\ Programa de Pós-Graduação em Informática (PPGI) - Universidade Federal do \\ Amazonas (UFAM) \\ Av. General Rodrigo Otávio, Coroado, Manaus - AM - Brasil \\ \{amml, jnetto\}eicomp.ufam.edu.br
}

\begin{abstract}
This article presents a Systematic Mapping of research related to Intelligent Tutoring Systems, focusing on the investigation of works carried out in the Brazilian context. The research is motivated due to the notes made by some researchers for this type of system that is becoming a global trend. Wherefore, this mapping investigates the Brazilian's ITS together with their respective application areas, the applied pedagogical theories, the educational levels addressed, seeking to outline a Brazilian panorama, aiming to contribute and assist in the development and expansion of knowledge about this technology within the national context.
\end{abstract}

Resumo. Este artigo apresenta um Mapeamento Sistemático sobre as pesquisas relacionada aos Sistemas Tutores Inteligentes, tendo enfoque na investigação de trabalhos realizados no contexto brasileiro. A pesquisa é motivada em virtude dos apontamentos realizados por alguns pesquisadores para esse tipo de sistema que vem se tornando uma tendência global. Com isso, este mapeamento investiga os STIs brasileiros juntamente com suas respectivas áreas de aplicação, as teorias pedagógicas aplicadas, os níveis educacionais abordados, buscando delinear um panorama brasileiro, visando contribuir e auxiliar no desenvolvimento e ampliação do conhecimento sobre essa tecnologia dentro do contexto nacional.

\section{Introdução}

Os Sistemas Tutores Inteligentes (STI) são ambientes de aprendizagem computadorizados que incorporam modelos computacionais multidisciplinares compreendendo as áreas das ciências cognitivas, ciências de aprendizagem, linguística computacional, Inteligência Artificial e outros campos [Graesser et al., 2012]. Segundo Han et al. (2019), os STIs podem efetivamente aprimorar a aquisição de conhecimento dos alunos, assim como a memorização, compreensão, aplicação, análise, síntese e avaliação, além disso, promover a transformação e a migração de conhecimento e auxiliar a alcançar resultados significativos de aprendizagem com eficiência e eficácia. O STI age como um agente de aprendizado que beneficia os usuários por meio da interação, aprendendo e apresentando soluções para os problemas [Silva, 2011].

Algumas revisões da literatura seguem incorporando discussões e identificando os STIs que apoiam a educação em um contexto global, como por exemplo: a eficácia dos STIs por meio de análise das avaliações controladas [Kulik \& Fletcher, 2016] e as tendências no desenvolvimento nas pesquisas sobre STIs [Han et al., 2019]. A pesquisa 
realizada por Carraro et al. (2019) também identificou os mais citados STIs da literatura global, utilizando como base as principais bibliotecas acadêmicas. Contemplando essa expansão pelo mundo dos STIs, é possível perceber que esses sistemas atendem uma variedade de usuários, além disso os benefícios que apresentam são significativos.

A partir da compreensão do atual estado da arte das publicações inerentes à temática de STIs, Vicari (2018) e Han et al. (2019) destacam que várias nações estão utilizando STIs e os evoluindo com as mais variadas tecnologias. Tais contribuições, promovem evolução nos campos de pesquisas, como por exemplo em áreas da Computação Afetiva, Processamentos de Linguagem Natural, Learning Analytics e outras, sempre visando o nível de adaptação e o sucesso educacional dos estudantes. Contudo, no contexto brasileiro, não encontramos uma pesquisa atual que descreva uma visão geral dos STIs, sobre os impacto e a relevância no desenvolvimento, assim como as áreas do conhecimento atendidas, os níveis educacionais, as técnicas de IA mais utilizadas e as teorias pedagógicas abordadas.

No Brasil, é possível observar várias iniciativas realizadas em diferentes regiões do país e publicadas nas principais conferências e revistas da área de Informática na Educação. Por isso, a presente pesquisa investiga os STIs desenvolvidos, buscando traçar um panorama nacional. O estudo aqui reportado, é um Mapeamento Sistemático (MS) que abrange as iniciativas e produções de STIs nos variados contextos e em diferentes áreas do conhecimento, a fim de delinear uma visão geral das iniciativas nacionais.

A presente pesquisa ganha relevância a partir do levantamento quantitativo e qualitativo realizado sobre as pesquisas envolvendo os STIs. O objetivo é nortear na compreensão das produção científica dos STIs nacionais e informar pesquisadores e educadores sobre as iniciativas tecnológicas que são produzidas para apoio educacional direcionado para os Sistemas Tutores Inteligentes.

\section{Processo do Mapeamento}

Segundo Petersen et al. (2008) o Mapeamento Sistemático (MS) apresenta uma estrutura de tipo de relatórios e resultados de pesquisas publicados por categorização para um cenário mais abrangente com o objetivo de reunir o máximo de informações. Muitas vezes, produz um resumo visual e/ou mapa dos resultados fornecendo uma visão geral e granular [Petersen et al., 2008].

O mapeamento geralmente visa classificar a literatura relevante e agregar estudos com relação às categorias definidas que são baseadas em informações das publicações (nome autores, afiliações dos autores, fontes de publicação, tipo de publicação, data publicação, etc.) e/ou informações sobre os métodos utilizados pelas pesquisas [Kitchenham et al., 2011]. Com base, este mapeamento foi conduzido nos processos descritos por Petersen et al., (2008) e estruturad o conforme mostra a Figura 1. O processo utilizado por esta pesquisa possui três fases: 1 - Definição da Pesquisa, 2 Coleta de estudos e 3 - Síntese dos Resultados.

$\mathrm{Na}$ fase 1 foi elaborado um protocolo a fim de guiar a pesquisa, por exemplo os objetivos, as questões de pesquisas e os critérios de inclusão e exclusão. Na segunda fase, foi realizada a busca por estudos primários, respeitando os critérios de inclusão e exclusão definidos. $\mathrm{Na}$ última fase, os estudos que atenderam os critérios, foram selecionados e mapeados de acordo com alguns esquemas de classificação. 


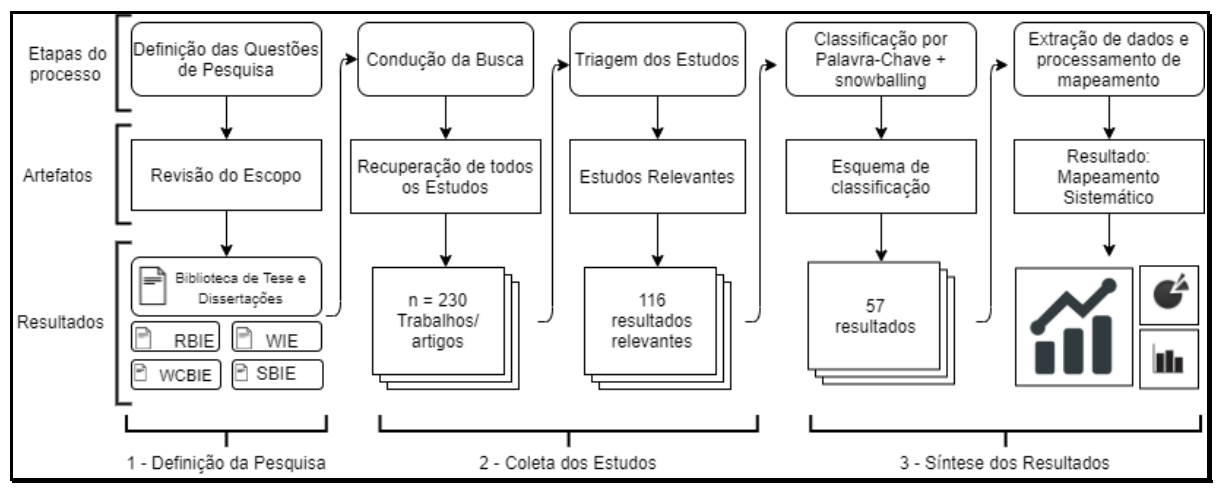

Figura 1. Resumo do Processo de Mapeamento Sistemático (adaptado de Petersen et al., 2008).

\subsection{Fase 1 - Definição da Pesquisa}

Como o objetivo deste estudo é identificar e caracterizar as pesquisas dos STIs no Brasil, foram elaboradas algumas questões de pesquisas específicas para auxiliar na investigação deste processo de mapeamento. Um conjunto de questionamentos fizeram parte do planejamento, sendo descritos no Quadro 1.

Quadro 1. Questões de pesquisa (QP) levantadas como parte do planejamento.

\begin{tabular}{|c|c|}
\hline QP1 & $\begin{array}{l}\text { Quais são as pesquisas que apresentam propostas de STIs? } \\
\text { Objetivo: identificar qua is são os STIs primários das pesquisas apresentadas, visando investigar } \\
\text { somente as que apresentam os módulos que compõem a arquitetura bá sica de um STI. }\end{array}$ \\
\hline QP2 & $\begin{array}{l}\text { Qual o quantitativo de pesquisas continuadas/extensão de cada um dos STIs } \\
\text { identificados? } \\
\text { Objetivo: identificar quantitativamente as contribuições dos STI identificados na QP1. Os } \\
\text { resultados serão utilizados para dar relevância às contribuições das respectivas pesquisas. }\end{array}$ \\
\hline QP3 & $\begin{array}{l}\text { Quais são as áreas do conhecimento abordadas pelos STIs? } \\
\text { Objetivo: identificar as áreas do conhecimento abordadas pelos STIs. }\end{array}$ \\
\hline QP4 & $\begin{array}{l}\text { Quais os níveis educacionais alcançados pelos STIs? } \\
\text { Objetivo: identificar os contextos educaciona is que os STI foram aplicados e avaliados. A QP } \\
\text { auxilia identificar o perfil dos usuários. }\end{array}$ \\
\hline QP5 & $\begin{array}{l}\text { Quais são as técnicas de Inteligência Artificial utilizadas e suas finalidades? } \\
\text { Objetivo: identificar os algoritmos da IA que estão sendo aplicados dentro do contexto de } \\
\text { Sistemas Tutores Inteligentes. }\end{array}$ \\
\hline QP6 & $\begin{array}{l}\text { Quais as teorias de aprendizagem e de ensino são abordadas pelos STIs relacionados? } \\
\text { Objetivo: identificar as teorias de aprendizagem que estão relacionada às execuções das } \\
\text { atividades dos STIs que visam modelar o estado cognitivo dos usuários (Rodrigues \& } \\
\text { Carvalho,2005). }\end{array}$ \\
\hline
\end{tabular}

Para a condução desta pesquisa foram escolhidas as bases de dados brasileiras com a finalidade de abranger as publicações científicas nacionais. Para isso, foram selecionadas as bases: Biblioteca Digital Brasileira de Teses e Dissertações (BDTD), Simpósio Brasileiro de Informática na Educação (SBIE), Revista Brasileira de Informática na Educação (RBIE), Workshop de Informática na Escola (WIE); Workshops do Congresso Brasileiro de Informática na Educação (WCBIE) e a Revista de Novas Tecnologias na Educação (RENOTE). A justificativa para essas escolhas é que, primeiramente, a BDTD, auxilia na identificação das propostas originárias dos STIs (QP1), as outras bases de dados, ajudam na identificação dos projetos de extensão inerente aos STIs encontrados (QP2). 
IX Congresso Brasileiro de Informática na Educação (CBIE 2020)

Anais do XXXI Simpósio Brasileiro de Informática na Educação (SBIE 2020)

\subsection{Fase 2 - Coleta de Dados}

Após a escolha das bases de pesquisas, foram definidos os termos que iriam compor a string de busca a ser inserido nas bases digitais, a expressão definida foi "intelligent tutoring systems" OR "sistemas tutores inteligentes" OR ("sistema*" AND "tutor" "AND "inteligente*"), optando pela utilização de aspas a fim de obter mais objetividade no processo de busca. As buscas foram realizadas no período de $1^{\circ}$ a 20 de junho de 2020 com trabalhos atendendo entre os anos 2000 à 2019. Portanto, este mapeamento está considerando apenas os trabalhos indexados até este período, resultand o em um total de 230 pesquisas distribuídas entre teses/dissertações e artigos.

Para o processo de triagem dos trabalhos, os critérios de inclusão e exclusão foram definidos no protocolo do planejamento. Considerando os objetivos desta pesquisa, os seguintes critérios de inclusão (CI) foram definidos: CI-1: Pesquisas que envolvam propostas de arquiteturas de STIs ou sistemas inteligentes nos aspectos de Modelo do Estudante, Modelo Domínio, Modelo Interface e Modelo Especialista. CI-2: A versão completa dos trabalhos deve estar disponível; CI-3: Os trabalhos devem estar escritos no idioma inglês ou português-BR. Todas as pesquisas que corresponderam aos critérios foram incluídas.

Os critérios de exclusão (CE) foram definidos: CE-1: O estudo não aborda proposta de arquitetura de um STI; CE-2: O estudo apresenta pesquisa continuada/extensão sobre algum outro STI já relacionado no CI-1. O CE-1, objetiva eliminar as pesquisas que apresentam propostas de Agentes Pedagógicos Animados como tutores inteligentes, mas que suas arquiteturas e modelos de tutoração não estão compatíveis com os loops (internos e externos) referente aos modelos básicos de um STIs [VanLehn, 2006]. O CE-2, é aplicado na segunda fase de leitura visando identificar as pesquisas continuadas de alguns dos STI identificados na primeira fase. Aplicando o CE-2, as pesquisas foram classificadas como "extensão" que resultou em um conjunto de 116 pesquisas aceitas (ver Figura 1).

$\mathrm{Na}$ terceira fase, após a aplicação do CE-2 foram elencados todos os STI que são descritos neste MS. Por fim, outras pesquisas também foram excluídas, com base nos seguintes critérios: pesquisas duplicadas (CE-3), não estavam relacionadas aos objetivos e QPs (CE-4) e pesquisas em short papers e white papers $(\mathbf{C E - 5 )}$.

\subsection{Fase 3 - Síntese dos Resultados}

$\mathrm{Na}$ última fase de seleção, todos os estudos relevantes foram submetidos à leitura completa. Cada um dos trabalhos foi analisado novamente, considerando os critérios de inclusão e exclusão. Em cada uma das pesquisas marcadas como "extensão", foi utilizada a técnica de Snowballing nível 1, com o objetivo de identificar os STIs originários das pesquisas (CI-1). Petersen et al. (2008) desconsideram a técnicas de snowballing, por isso, este estudo empreendeu uma adaptação nas fases de mapeamento.

Por fim, um total de 57 estudos foram aprovados e 58 estudos foram rejeitados conforme o (CE-2). Devido à falta de espaço para detalhamento, a lista dos STIs pode ser conferida no link: https://cutt.ly/LfVw2OG.

Em resumo, os achados mostraram que o STI PAT2Math apresentou um maior quantitativo de contribuições. O STI MAZK, apresentou uma evolução desde um ambiente inteligente até tornar-se um STI que atende desde o Ensino Fundamental ao 
Ensino Superior, o mesmo ocorrendo com o STI SAE. No aspecto voltado aos níveis de ensino, a maioria das pesquisas abord ou o Ensino Superior, principalmente nas áreas de ensino da Programação e Lógica Matemática. As estratégias de ensino que foram identificadas neste MS foram: a Aprendizagem Baseada em Casos, simulação, treinamento e os métodos socráticos.

\section{Resultados}

Do total das 230 pesquisas identificadas na primeira fase, 57 delas apresentaram propostas de STIs que se desenvolveram ao longo dos anos, contribuindo com a evolução tecnológica das próprias propostas, assim como no aprimoramento do ensino formal e informal. As (QPs) elaboradas na fase de planejamento (ver Quadro 1) são discutid as a seguir.

- QP1 - Quais são as pesquisas que apresentaram propostas de STIs? QP2 - Qual o quantitativo de pesquisas continuadas/extensão de cada um dos STIs identificados?

A Figura 2 apresenta os achados identificados neste MS, unificando as QP1 e QP2. Em resposta à QP1, foram encontrados um total de 57 STIs.

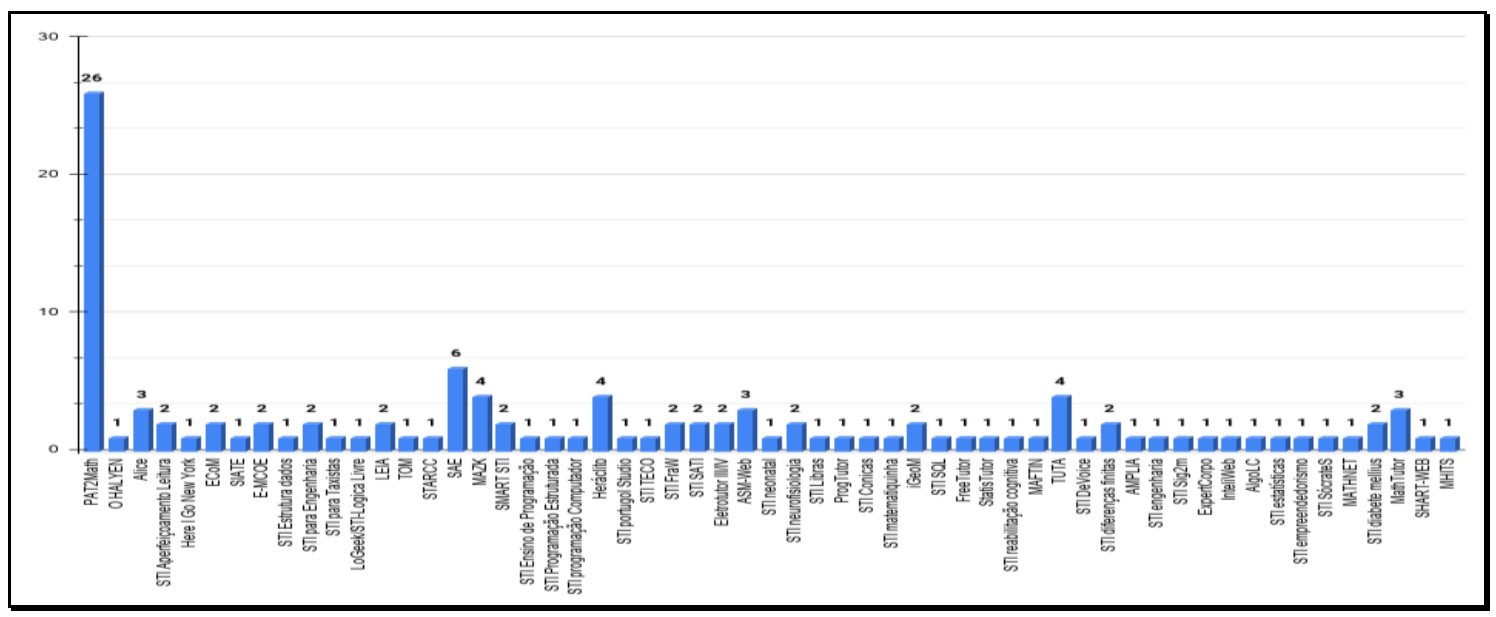

Figura 2. Os STIs relacionados neste Mapeamento Sistemático (QP1) e o número de contribuições atribuídas por cada uma das pesquisas (QP2).

Em relação à QP2, a Figura 2 mostra o STI PAT2Math com 26 publicações nacionais identificadas, seguido pelo STI SAE com um total de 6 publicações. Logo, em seguida o STI MAZK e Heráclito com 4 publicações cada. ALICE, ASM-Web e MathTutor com 3 contribuições. Para mais detalhes, a relação dos STIs com as respectivas contribuições pode ser conferida no link: https://cutt.ly/9fVw9J9.

Nos resultados apresentados na Figura 2, os STIs que possuem maior quantitativo de contribuições muito provavelmente estão relacionados ao desenvolvimento modular ou inserção de novas funcionalidades e tecnologias na arquitetura. Por exemplo, o STI PAT2Math, contribuiu apresentando a construção de cada um dos componentes que pertencem à arquitetura, indo desde o módulo resolvedor de equações, à modelagem do conhecimento do estudante, inserção de agentes pedagógicos animados e entrada por escrita à mão.

Outro exemplo, é o STI SAE que apresentou o desenvolvimento de novos módulos no sistema, como o aprimoramento dos módulos de tutoria e o auxílio no 
acompanhamento dos estudantes. O STI LEIA ampliou-se no desenvolvimento de um módulo de diagnósticos baseados em algoritmos fuzzy para modelar o conhecimento dos alunos. O STI Heráclito, tem suas contribuições voltadas para modelagem dos estudantes e aprimoramento do módulo especialista do sistema. O ASM-Web incrementou novas tecnologias baseadas nos modelos de visualização 3D para auxiliar no processo de ensino e aprendizagem. Por fim, a maioria dos achados, apresentou artigos que estão correlacionados às propostas das teses e dissertações.

- QP3 - Quais são as áreas do conhecimento abordadas pelos STIs?

A Tabela 1, resume as áreas do conhecimento abordados e os respectivos STIs encontrados neste MS. É notável o predomínio de mais da metade dos STIs abordarem o campo das Ciência Exatas com 53,42\%, constatado.

Tabela 1. Áreas do Conhecimento abrangidas pelos STIs.

\begin{tabular}{|c|c|c|c|}
\hline $\begin{array}{c}\text { Área do } \\
\text { Conhecimento }\end{array}$ & Áreas específicas & $\begin{array}{c}N^{\circ} \text { de } \\
\text { STIs }(\%)\end{array}$ & STIs \\
\hline Matemática & $\begin{array}{c}\text { Álgebra, Fração, Sistema decimal, } \\
\text { Geometria, Estatística, Cônicas, } \\
\text { Lógica proposicional, Lógica } \\
\text { Temporal }\end{array}$ & $20,68 \%$ & $\begin{array}{l}\text { PAT2Math, LEIA, Fra W, } \\
\text { matematiquinha, iGeoM, } \\
\text { StatisTutor, Maftin, STI-Logica } \\
\text { Livre, Herá clito, MoFACTS, } \\
\text { SMART STI. }\end{array}$ \\
\hline Contabilidade & $\begin{array}{l}\text { História Contabilidade, Matemática } \\
\text { Financeira. }\end{array}$ & $3,44 \%$ & Maftin, STARCC. \\
\hline $\begin{array}{l}\text { Ciência da } \\
\text { Computa ção }\end{array}$ & $\begin{array}{l}\text { Programação OO, Portugol, } \\
\text { Arquitetura de Computadores }\end{array}$ & $25,86 \%$ & $\begin{array}{l}\text { OHALYEN; ALICE; SIATE, } \\
\text { PROGTUTOR, TUTA; } \\
\text { AlgoLC; STI SócrateS; } \\
\text { MathTutor, MAZK. }\end{array}$ \\
\hline Física & Carga Elementar, Óptica Geométrica & $3,44 \%$ & EletroTutor III/IV, TECO. \\
\hline Linguagem & Libras, Inglês & $3,44 \%$ & - \\
\hline Biologia & $\begin{array}{c}\text { Neurofisiologia, cadeia a limentar, } \\
\text { ana tomia humana, ecologia, } \\
\text { anatomia vegetal }\end{array}$ & $8.62 \%$ & $\begin{array}{l}\text { ECoM, E-MCOE, ASM-Web, } \\
\text { InteliWeb, AMPLIA. }\end{array}$ \\
\hline Música & Harmonia Musical & $3,44 \%$ & SHART-WEB, MHITS. \\
\hline Outros & $\begin{array}{l}\text { Pesquisa de imagens, a locação de } \\
\text { materia is, diabete mellius, } \\
\text { empreendedorismo, gestão de } \\
\text { ma teria is e medicamentos, } \\
\text { reabilitação cognitiva, tra cotonomia } \\
\text { emergencial e outros. }\end{array}$ & $31,03 \%$ & $\begin{array}{l}\text { *STIs não tiveram seus nomes } \\
\text { definidos. }\end{array}$ \\
\hline
\end{tabular}

Conforme a Tabela 1, dentre os STIs que abrangem a área de Exatas, os que estão em maioria são os STIs voltados para o ensino de Programação e Arquitetura de Computadores $(25,86 \%)$, seguido pelos STIs que auxiliam no ensino e aprendizagem dos temas voltados para o campo da Matemática com um total de 20,68\%. Ainda, as áreas de Física com 3,44\% e Contabilidade com 3,44\%, complementam os achados.

Com relação à área de Linguagem e suas Tecnologias, foi atendido por apenas $3,44 \%$ dos STIs. As áreas biológicas foram à terceira identificada e explorada pela temática de Sistemas Tutores, com um total de 8,62\%. O campo das artes foi abordado por apenas dois STIs que auxiliaram no ensino de conceitos de música. No total restante $(31,03 \%)$, os STIs atenderam a assuntos diversos, como treinamento na área da saúde, na identificação da Diabete Mellitus e para curso básico de empreendedorismo. Houve, 
também, STIs desenvolvidos para treinamento de agentes do governo na área de logística para ensino de alocação de materiais e gestão de medicamentos.

Por fim, apenas dois STIs tiveram como temática a Reabilitação Cognitiva de alunos com alguma necessidade especial. Isso reflete que no caso das pesquisas voltados para a Educação Especial, as características facilitadoras das tecnologias se encaixam perfeitamente, mas apesar das dificuldades para desenvolvimento e implementação, os ambientes educacionais em grande parte ainda precisam se adequar em termos de infraestruturas e tecnologias [Mourão \& Netto, 2016].

- QP4 - Quais os níveis educacionais alcançados pelos STIs?

Os STIs identificados neste MS, têm sua aplicabilidade em cinco níveis educacionais, sendo: o Ensino Fundamental (EF), Ensino Médio (EM), Ensino Superior (ES), Técnico (Treinamento) e a Educação Especial (EE), conforme mostra a Figura 3.

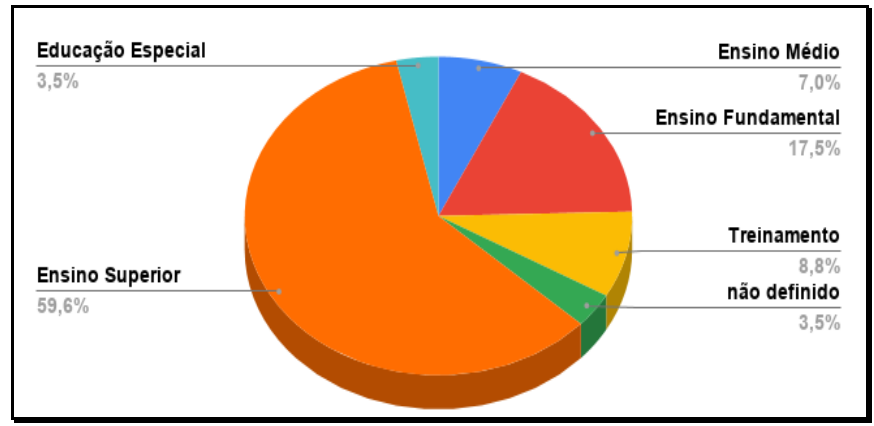

Figura 3. Níveis Educacionais identificados nas pesquisas de STIs.

De acordo com a Figura 3, o destaque está para o (ES) atendido em 59,6\% das pesquisas. Isso, representa o número de STIs que estão voltados para o ensino de assuntos sobre Programação, Arquitetura de Computadores e de Lógica Proposicional, sendo as temáticas fundamentais nos cursos de tecnologias e afins. O (EF) foi abordado em $17,5 \%$ das pesquisas. O resultado expressa os STIs que estão voltadas para o ensino de conteúdos básicos, como a Álgebra Básica, leitura, sistema decimal, Geografia, biologia dos vegetais e outros.

A influência do (ES) na aplicação dos STIs, pode ser analisada na perspectiva de que a maioria das pesquisas foram direcionadas para os cursos de Computação e afins. Como ainda há poucas pesquisas que divulgam projetos da área de computação para a Educação Básica [Ferri \& Dos Santos Rosa, 2017], entende-se que isso pode mudar no momento em que as áreas da computação façam parte da grade curricular da Educação Básica, assim como é realizado nos países desenvolvidos [Rocha \& Junior, 2020].

Outros 8,8\% das pesquisas dos STIs estão voltados para treinamento técnico nas áreas de Medicina e Logística. O (EM) foi abordado em 7\% das pesquisas. Em grande parte da aplicação dos STIs para o EM, está voltada para revisão de conteúdos básicos que representam a lacuna no conhecimento dos alunos, por exemplo conteúdos da Álgebra, Geografia e História.

Contudo, neste MS, ainda foram identificados os STIs que atenderam estudantes com necessidades especiais na ótica da educação inclusiva, representando 3,5\% das pesquisas. Enfatizando, os STIs foram desenvolvidos para o ensino de Libras e outro especificamente para Reabilitação Cognitiva, por exemplo o STI DeVoice. O DeVoice 
tem como base o ensino realizado por meio da pesquisa de imagens por entrada de voz. É importante destacar que as iniciativas para a EE, abrem precedentes para pesquisas sobre novas formas de interação e adaptação [dos Santos Jr et al., 2019].

- QP5 - Quais são as técnicas de Inteligência Artificial utilizadas e suas finalidades?

Em resposta à QP5, foram identificadas algumas técnicas de IA em uso nos STIs. As Árvores de Decisão (if-else) foram identificadas na maiorias das pesquisas, pois é comum o uso desta técnica nos modelos pedagógicos para tomada de decisão do ciclo de tutoração. Multiagentes, Ontologias (STI Fraw, AMPLIA), Modelos de Estados Mentais (X-BDI) (EletroTutor, MAFTIN, InteliWeb), Redes Bayesianas (STI PAT2Math) e Lógica Fuzzy (STI LEIA, STI Heráclito, STI-Lógica Livre) são utilizados para auxiliar na adaptação de conteúdos e modelagem do conhecimento dos estudantes.

Outros exemplos identificados, são os STIs ExpertCorpo e FreeTutor que utilizaram técnicas de Mineração de Dados (Clustering) e Redes Neurais Artificiais (RNA) para identificar padrões de comportamento dos estudantes e realizar navegação adaptativa. Em geral, a personalização do processo de aprendizagem dos STIs está cada vez mais contando com a aplicação de técnicas de RNA, contando com características adaptativas e reativas, capaz de oferecer ensino personalizado e dinâmico. As características dos perfis psicológicos dos estudantes são utilizados na maioria dos modelos de RNA como elementos para personalização e como forma de identificação dos estados afetivos (PAT2Math). Cabe destacar, as limitações das arquiteturas e capacidade de processamento que são fatores que colaboram para o sucesso/insucesso dos modelos de RNA propostos.

- QP6 - Quais são as teorias de ensino e aprendizagem abordadas pelos STIs?

Para responder à QP6, foram consideradas as pesquisas que mencionaram explicitamente a descrição das Teorias de Aprendizagem (TA) utilizadas. As TAs, auxiliam no desenvolvimento de hipóteses que descrevem como o processo de aprendizagem ocorre [Huang et al., 2019]. Assim, com base nas pesquisas de [Da Costa et al., 1997] e [Huang et al., 2019], foram identificadas as TAs.

Neste MS, foram identificadas as seguintes teorias: a Teoria de Assimilação Cognitiva (David P. Ausubel) e a Teoria do Desenvolvimento Cognitivo (Jean Piaget). Como exemplo, os STI SAE, FreeTutor, STI TECO baseiam-se nessas teorias. A Teoria de Mapeamento de Conceito (Joseph D. Novak) também teve influência em algumas pesquisas, por exemplo, no STI TOM e StatisTutor.

Em grande parte, a abordagem pedagógica dos STIs, é idealizada pela interação que é privilegiada por meio da aprendizagem colaborativa, com o uso da linguagem, símbolos e sinais, podendo ser interpretados na visão socioconstrutivista de Vygotsky [Huang et al., 2019]. O Socioconstrutivismo, neste caso, é abordado em grande parte pelos STIs identificados, tendo este, semelhanças das práticas interacionistas apontadas, também, por Paulo Freire ${ }^{1}$, influente pedagogo nacional. Por outro lado, essas TAs, também têm suas influências nos modelos computacionais, como o conceito da Zona de Desenvolvimento Proximal (ZDP) de Vygotsky. Esta teoria é explicitamente identificada nos modelos computacionais dos STIs LEIA, MAFTIN e PAT2Math.

\footnotetext{
${ }^{1}$ Ostermann, F., \& Cavalcanti, C. D. H. (2011). Teorias de aprendizagem. Porto Alegre: Evangraf.
} 
Junto às TAs, foram identificadas as estratégias de ensino mais utilizadas nos STIs. De modo geral, a maioria das estratégias teve como base os métodos de práticas de treino (aprenda fazendo) e estratégias baseadas em casos, voltadas para as práticas de Programação e Matemática. Os STIs voltados para as áreas biológicas, utilizaram métodos baseados em casos e simulações, utilizando tecnologia 3D como auxílio. As áreas voltadas para artes e humanas apresentaram métodos socráticos.

\section{Conclusões}

Este artigo apresentou um Mapeamento Sistemático (MS) das iniciativas brasileiras no campo de Sistemas Tutores Inteligentes (STI). Pesquisando em seis diferentes bases, foram identificados 57 STIs selecionados com base nos critérios de inclusão e exclusão. Neste MS foi avaliado um único STI para cada pesquisa encontrada. Uma breve descrição foi realizada com o intuito de auxiliar demais pesquisadores, visando melhorias nos paradigmas e aos educadores para informar sobre as novidades tecnológicas baseadas em STIs que podem auxiliar o processo de ensino e aprendizagem em diferentes áreas do conhecimento.

A influência em maior parte do desenvolvimento dos STIs foi para o Ensino Superior (59,6\%) com maioria dos assuntos ligados à áreas da Computação (25,86\%). As pesquisas dirigidas para o Ensino Fundamental apresentaram 17,5\%. Contudo, além dos STIs voltados para os modelos do ensino regular, foram identificados os STIs que auxiliam estudantes com necessidades especiais. Entre as diferentes Teorias de Aprendizagem identificadas, as mais citadas foram: a Teoria de Assimilação Cognitiva, a Teoria do Desenvolvimento Cognitivo e o Socioconstrutivismo que visam contribuir para a modelagem dos usuários dentro dos sistemas junto aos algoritmos de IA mais utilizados, dentre eles Árvores de Decisão, Redes Bayesianas e Lógica Fuzzy.

Por fim, a relevância do tema está ligada às características dos STIs e à variedade de aplicações. Isso indica um horizonte promissor para o desenvolvimento desta tecnologia no apoio educacional, além disso confirma os apontamentos realizados por Vicari (2018) e Huang et al. (2019). Para as regiões brasileiras que apresentaram poucos ou nenhum trabalho identificado neste MS, cabe sugerir alguns estudos com base nos questionamento e de algumas das dificuldades relatadas por Nye (2015). Destaca-se, que nos achados deste MS, as técnicas utilizadas pelos STIs estão cada vez mais sendo integradas em novos ambientes educacionais digitais, como exemplo nos MOOCs e AVAs, com foco na modelagem e adaptação personalizada dos estudantes. Por isso, essa pesquisa permite nortear o desenvolvimento em novos contextos e auxiliar novas pesquisa voltado para os STIs de âmbito nacional.

\section{Limitações deste Mapeamento}

A utilização de um conjunto limitado de base de dados (ver Seção 2.1) pode ocasionar que estudos relevantes não tenham sido considerados ou relacionados nesta pesquisa. Além disso, as terminologias utilizadas em alguns trabalhos ou foco das pesquisas também possam não terem sido achados pela string de busca proposta (ver Seção 2.2).

\section{Agradecimentos}

O presente trabalho foi realizado com o apoio da FAPEAM (Fundação de Amparo à Pesquisa do Estado do Amazonas) e PROSGRAD/UFAM (Programa de Apoio à PósGraduação Stricto Senso) sob a resolução nº 006/2020. 
IX Congresso Brasileiro de Informática na Educação (CBIE 2020)

Anais do XXXI Simpósio Brasileiro de Informática na Educação (SBIE 2020)

\section{Referências}

Carraro, J. A. da R., Valeriano, E. C. de F., \& Pozzebon, E. (2019). Sistemas Tutores Inteligentes: Revisão Bibliográfica Sistemática do Conteúdo Literário. ARTEFACTUM - Revista de Estudos em Linguagem e Tecnologia, v. 18, $\mathrm{n}^{\mathrm{o}} 1$.

Da Costa, R., Santos, N., \& Da Rocha, A. R. C. (1997). Diretrizes pedagógicas para modelagem de usuário em sistemas tutoria is inteligentes. Universidade Federal do Rio de Janeiro-UFRJ, COPPEPrograma de Engenharia de Sistemas e Computação.

$<$ http://www.tise.cl/2010/archivos/tise97/trabajos/trabajo11/>. Acessa do em 23 de setembro de 2020.

dos Santos Jr, F. D., Barone, D. A. C., Wives, L., \& Kuhn, I. (2019). Inteligência Artificial e Educação Especial: Desafios Éticos. Ana is do Workshop de Desafios da Computação Aplicada à Educação, v. 8, $\mathrm{n}^{\mathrm{o}} 1, \mathrm{p} .13$.

Ferri, J., \& Dos Santos Rosa, S. (2017). Como o Ensino de Programação de Computadores Pode Contribuir Com a Construção de Conhecimento na Educação Básica Uma Revisão Sistemática da Literatura. RENOTE, v. 14, nº 2 .

Graesser, A. C., Conley, M. W., \& Olney, A. (2012). Intelligent tutoring systems. In K. R. Harris, S. Graham, T. Urdan, A. G. Bus, S. Major, \& H. L. Swanson (Orgs.), APA educational psychology handbook, Vol 3: Application to learning and teaching. (p. 451-473). American Psychological Association.

Han, J., Zhao, W., Jiang, Q., Oubibi, M., \& Hu, X. (2019). Intelligent Tutoring System Trends 20062018: A Literature Review. 2019 Eighth InternationalConference on Educational Innovation through Technology (EITT), p. 153-159.

Huang, R., Spector, J. M., \& Yang, J. (2019). Educational Technology: A Primer for the 21 st Century. Springer Singapore. https://doi.org/10.1007/978-981-13-6643-7.

Kitchenham, B. A., Budgen, D., \& Pearl Brereton, O. (2011). Using mapping studies as the basis for further research - A participant-observer case study. Information and Software Technology, v. 53, $\mathrm{n}^{\circ}$ 6, p. 638-651.

Kulik, J. A., \& Fletcher, J. D. (2016). Effectiveness of Intelligent Tutoring Systems: A Meta-Analytic Review. Review of EducationalResearch, v. 86, $\mathrm{n}^{\mathrm{o}} 1$, p. 42-78.

Mourão, A.; \& Netto, J. F. M. (2016). Modelo Inclusivo de Desenvolvimento e Avaliação de Objetos de Aprendizagem Acessível voltados para o Ensino Superior em Computação. XXVII Simpósio Bra sileiro de Informática na Educação (SBIE), vol. 27, nº 1, p. 698.

Nye, B. D. (2015). Intelligent Tutoring Systems by and for the Developing World: A Review of Trends and Approaches for Educational Technology in a Global Context. International Journal of Artificial Intelligence in Education, v. 25, $\mathrm{n}^{\mathrm{o}} 2$, p. 177-203.

Petersen, K., Feldt, R., Mujtaba, S., \& Mattsson, M. (2008). Systematic Mapping Studies in Software Engineering. 12th International Conference on Evaluation and Assessment in Software Engineering (EASE), v. 12, p. 1-10.

Rocha, J. S., \& Junior, G. C. (2020). A Implementação da Linguagem de Programação na Educação Escolar Utilizando o Scratch. Revista Educa Online, v. 14, nº 22, p. 45-66.

Rodrigues, L. M. L., \& Carvalho, M. (2005). STI-I: Sistemas Tutoriais Inteligentes que Integram Cognição, Emoção e Motivação. Revista Bra sileira de Informática na Educação,v. 13, nº 1, p. 7-11.

Silva, V. dos S. (2011). Tutores Inteligentes Como Mediador Para o Ensino e Aprendizagem. Tecnologias em Projeção,v. 2, nº 1, p. 29-33.

VanLehn, K. (2006). The Behavior of Tutoring Systems. International Journal of Artificial Intelligence in Education, v.16, $\mathrm{n}^{\circ} 3$, p. 227-265.

Vicari, R. M. (2018). Tendências em inteligência artificial na educação no período de 2017 a 2030 : SUMÁRIO EXECUTIVO/Serviço Nacional de Aprendizagem Industrial, Serviço Social da Indústria. SENAI. $<$ http://lazerativo.sesi.org.br/bitstream/uniepro/259/1/Sumario_tendencias_web.pdf $>$. Acessado em 23 de setembro de 2020. 